\title{
Intestinal Ischemic Preconditioning Modulates Oxidative Stress in Rat's Spinal Cord Ischemic Reperfusion Injury
}

\author{
Salah O Bashir ${ }^{(1)}$, Ossama A. Mostafa ${ }^{(2)}$, Mohamed S Rizk ${ }^{(3)}$, Mamduoh R Al-Ridi( ${ }^{(4)}$ \\ Mohamed D Morsy ${ }^{*}(1)$
}

\author{
${ }^{(1)}$ Physiology Department, College of Medicine, King Khalid University, Saudi Arabia \\ ${ }^{(2)}$ Public Health Department, Faculty of Medicine, Beni Suef University, Egypt \\ ${ }^{(3)}$ Biochemistry Department, College of Medicine, Menoufiya University, Egypt \\ ${ }^{(4)}$ Department of Physiology, Faculty of Medicine (Rabigh Branch), King Abdul Aziz University, Saudi Arabia \\ * Corresponding author: \\ Mohamed Darwesh Morsy \\ Physiology Department \\ College of Medicine \\ King Khalid University \\ Saudi Arabia \\ Tel: +966544495223 \\ Fax: +96672418194 \\ E-mail: morsydarwesh@yahoo.com
}

\begin{tabular}{l|l|l|l|l|} 
Received: 24 January 2012; & Revised: 16 April 2012; & Accepted: 8 May 2012
\end{tabular}

\begin{abstract}
Background: Paraplegia is a major devastating and unpredictable complication of spinal cord ischemic reperfusion injury (SC-IRI). Ischemic preconditioning (IPC) is a procedure whereby a brief episode of non-lethal ischemia to an organ produces protection against subsequent detrimental ischemic-reperfusion insult to that organ. It has been shown that IPC may not only induce a local protective effect, but also induces resistant to ischemic-reperfusion damage in remote organs what is termed remote ischemic preconditioning (rIPC).

Aim: The aim of the present study was to investigate the potential protective effect of small intestinal ischemic preconditioning on subsequently induced SC-IRI in rats.

Methods: Fifty male Sprague-Dawley rats were randomly divided into five groups ( $\mathrm{n}=10$ each): control rats (C) which underwent no surgery; Sham rats (S) were subjected to laparotomy without induction of rIPC or clamping of the aorta; remote intestinal ischemic preconditioning group (rIPC) were subjected to 3 cycles of 8-min anterior mesenteric artery occlusion followed by 5-minute reperfusion; SC-IRI rats were subjected to laparotomy with clamping of the aorta just above the bifurcation by non-traumatic vascular clamp for 45 minutes, then the clamp was released for reperfusion for 24 hours; and SC-IRI+rIPC rats underwent 3 cycles of 8-minute anterior mesenteric artery occlusion followed by 5 -minute reperfusion each. Twenty four hours later, animals underwent another laparotomy and spinal cord ischemia followed by reperfusion similar to group SC-IRI. Twenty four hours after surgery; neurological assessment was done. Serum tumor necrosis factor alpha $(\mathrm{TNF}-\alpha)$, spinal cord homogenate levels of prostaglandin $\mathrm{E}_{2}\left(\mathrm{PGE}_{2}\right)$,
\end{abstract}


malondialdehyde (MDA) and advanced oxidative protein product (AOPP) and nitrite/nitrate (NOx) as well as superoxide dismutase (SOD) and catalase (CAT) activities were assessed. Small intestinal MDA homogenate levels and CAT activities were also measured.

Results: Induction of intestinal rIPC 24 hours before SC-IRI produced significant reduction of the serum TNF- $\alpha$, and spinal cord homogenate levels of $\mathrm{PGE}_{2}, \mathrm{MDA}$, AOPP and NOx as well as a significant reduction of SOD and a significant increase in CAT activity levels compared with the SC-IRI group.

Conclusions: Remote small intestinal ischemic preconditioning ameliorated the clinical neurological dysfunction induced by ischemic reperfusion injury of spinal cord. This ameliorating effect appears to be through improvement of the oxidative stress level, lipid peroxidation and the preservation of SOD and CAT activities in the spinal cord.

Keywords: spinal cord ischemia, remote preconditioning, intestinal ischemia, oxidative stress, thoracoabdominal aneurismal repair.

\section{Introduction}

Severe neurological injury still represents one of the most disastrous complications occurring after surgical repair of thoraco-abdominal aneurysms due to spinal cord ischemic reperfusion injury (SC-IRI) [1]. However, conventional strategies for preventing paraplegia due to spinal cord ischemia provide insufficient protection and cause additional side effects [2]. The pathophysiological mechanisms of neuronal damage during SC-IRI involve the production of free radicals, lipid peroxidation, intracellular calcium deposition, and apoptosis [3]. Free radicals, particularly reactive oxygen or nitrogen intermediates, are thought to be involved in inflammatory processes, exacerbating inflammation, and causing tissue damage [4]. It has been reported that ischemia induces oxidative stress, leading to induction and expression of various genes in a variety of cell types throughout the central nervous system [5]. One of those important genes is the cyclooxygenase enzyme $(\mathrm{COX})$ gene. This enzyme is the rate-limiting enzyme involved in arachidonic acid metabolism, with subsequent generation of prostaglandins and thromboxanes that play important roles in sustaining the inflammatory response and inducing different neurological deficits [6]. It was also found that, elements of oxidative stress are essential for the activation of COX enzyme [7]. On the other hand, inflammatory mediators increase nitric oxide (NO) production during ischemic reperfusion injury in tissues by activation of induced nitric oxide synthase (iNOS). Excessive NO interacts with superoxide anion to form a toxic product, peroxynitrite with subsequent oxidative injury. So, it was suggested that a vicious cycle is created between oxidative stress and inflammatory mediators [8].

Ischemic preconditioning (IPC) is a procedure whereby a brief episode of non-lethal ischemia produces protection against a subsequent detrimental ischemia-reperfusion insult (ischemic tolerance) [9]. IPC is perhaps the most powerful endogenous protective mechanism to protect against ischemic reperfusion injury in cardiac and non-cardiac tissues [10]. Recently, it was reported that, a transient ischemic episode in one organ not only augments the ischemic tolerance within the same organ but may also have a remote effect on other organs [11]. This phenomenon of cross tolerance has been termed 'remote ischemic preconditioning' (rIPC). Remote renal IPC protection is reported to exist in animals and humans [12]. Remote IPC of the small intestine elicits not only a local protective effect, but also protects remote organs like the heart during cardiac ischemic reperfusion injury [10]. Dong et al. reported that rIPC by transient hind limbs ischemia resulted in resistance of the spinal cord to ischemia and tissue damage [1]. However, little attention has been paid to spinal cord protection by remote organ IPC.

Several studies have shown that rIPC has a protective effect which follows two different time scales, classified as 'short-term' and 'long-term' effects of rIPC "second window of protection" [13]. The protective effect of short-term rIPC lasts 
for 2-3 hours after ischemic insult during which adenosine, bradykinin, norepinephrine and opioids are released. These compounds prevent damage by activation of the potassium channels and increasing ATP stores [14]. The long term protective mechanism of rIPC begins 12-24 hours after ischemia and involves iNOS, COX-2 activities and heat shock proteins [13].

Small intestinal rIPC protective effects on neurological tissues have not been fully clarified and addressed. So, the aim of this study was to investigate the possible protective effect of longterm small intestine rIPC on the spinal cord against oxidative stress damage caused by ischemic reperfusion injury. This was achieved through assessment of changes spinal cord oxidative stress and inflammatory mediators' levels, associated with SC-IRI.

\section{Methods}

All animals received human care in compliance with the Public Health Service Policy on Human Care and Use of Laboratory Animals, published by the National Institutes of Health and were approved by the Ethical Committee of the College of Medicine, Menoufiya University, Egypt.

\subsection{Experimental animals}

This study followed a randomized controlled animal experiment design. At the start of the experiment, a total of 80 male SpragueDawley rats were obtained from the animal house of King Khalid University, weighed between 150 - 200 gm. Animals were fed on a standard chow diet, water, ad libitum and housed in the animal house of faculty of Medicine with a 12:12-hour light/dark cycle. Animals with any motor deficit; limping or abnormal placing/stepping reflex had been excluded. The apparent healthy animals were randomly divided into five groups ( $\mathrm{n}=10$ each) as follows: $C$ control rats which underwent no surgery; Sham rats were subjected to laparotomy without clamping of the aorta or induction of IPC; intestinal IPC group were subjected to 3 cycles of 8-minute anterior mesenteric artery occlusion followed by 5 -minute reperfusion without SC-IRI [14]; SC-IRI rats were subjected to laparotomy with clamping of the aorta, just above its bifurcation by non-traumatic vascular clamp for 45 minutes, then the clamp was released for reperfusion for 24 hours. SC-IRI+IPC rats underwent 3 cycles of anterior mesenteric artery occlusion, followed by reperfusion as in sham group. Twenty four hours later, the animals of this group were subjected to another laparotomy and spinal cord ischemia was performed, followed by reperfusion as in group SC-IRI. The reason for producing the transient IPC of the small intestine 24 hours ahead of SC-IRI and reperfusion for another 24 hours in our study was to benefit from the long-term effect of IPC.

\subsection{Induction of intestinal ischemic preconditioning and ischemic reperfusion injury of the spinal cord}

Intestinal IPC was induced in IPC and SCIRI+IPC groups: Feeding of the animals was stopped 12 hours prior to the start of the intestinal IPC procedure and they received only water. Each rat received $150 \mathrm{IU} / \mathrm{kg}$ heparin i.p. and was anesthetized with sodium pentobarbital $(60 \mathrm{mg} / \mathrm{kg}$ i.p.). The anterior mesenteric arteries were dissected free, and a suture was placed around the arteries to facilitate occlusion. Occlusion of the anterior mesenteric arteries with a nontraumatic microvascular clamp caused ischemia. Ischemia was recognized by the absence of pulse and pale color of the intestine. Reperfusion was achieved by releasing the clamp. This procedure was done for 3 cycles (each lasting for 8 minutes of ischemia followed by 5 minutes for reperfusion). The abdomen was then closed and fluid losses were replaced by i.p. administration of $5 \mathrm{ml}$ of pre-warmed $\left(37^{\circ} \mathrm{C}\right)$ isotonic saline after surgery [14].

Spinal cord ischemia was induced in SCIRI and SC-IRI+IPC rats, as described by Akguna et al. [15]. Rats were initially anesthetized with i.m. ketamine $(50 \mathrm{mg} / \mathrm{kg})$, followed by a half dose as required during the procedure. The animals did not receive ventilatory support. Body temperature was monitored by a rectal probe and was maintained between $37^{\circ} \mathrm{C}-38^{\circ} \mathrm{C}$ by a thermal pad and a heating lamp. The femoral artery was cannulated with a 22-gauge PE catheter, which was used to monitor distal arterial pressure (DAP) 
and for intra-arterial infusion of heparin. The left carotid artery was cannulated with a 20 -gauge PE catheter (Terumo, Tokyo, Japan), which was used to monitor the proximal artery pressure (PAP) and to take blood samples. Each rat received 150 IU/kg heparin injected into the femoral artery immediately after completion of arterial cannulation and before aortic occlusion. The abdominal aorta was reached through midline laparotomy. Animals were then subjected to aortic cross clamping by non-traumatic vascular clamp placed under the left renal vein and above the bifurcation of the aorta for 45 minutes. The success of occlusion was documented by an immediate and sustained decrease in DAP in the femoral artery. To maintain the PAP approximately at $40 \mathrm{mmHg}$ during occlusion, blood from the carotid artery was allowed to flow into a collecting circuit filled with heparinized saline (4 U/ml of saline) positioned $54 \mathrm{~cm}$ above the rat. The temperature of the blood in the syringe was maintained at $37-37.5^{\circ} \mathrm{C}$. The aortic clamps were released after 45 minutes and the blood in the syringe was transfused back into the rat over a 60 -second period. After completion of all procedures, the wounds were closed. Immediately after surgery, animals were rehydrated with 5 $\mathrm{ml} / \mathrm{kg}$ i.p. pre-warmed isotonic saline $\left(37^{\circ} \mathrm{C}\right)$. The abdominal incision was closed in two layers with silk suture and protamine sulfate $(4 \mathrm{mg}$ ) was subcutaneously injected to reverse the anticoagulation effect of heparin. Animals were allowed to recover in a plastic box at $28^{\circ} \mathrm{C}$ for 3 hours and were then placed in their cages with free access to food and water [16]. Rats with complete hind limb paralysis for 24 hours, hematuria, or $25 \%$ reduction in body weight were killed using a lethal dose of thiopental sodium injection (75 $\mathrm{mg} / \mathrm{kg}$ i.p.) for humanitarian reasons. The survival rate in IPC group was $90 \%$, in SC-IRI group was $60 \%$ and SC-IRI+IPC was $90 \%$. One rat of the sham group died from surgical trauma during the operation. In spite of these different survival rates we included 10 living rats in each group to be involved in the study.

\subsection{Neurological assessment}

After 24 hours from the second surgical procedures for group SC-IRI+IPC and after 24 hours from the surgical procedures in group SCIRI and 48 hours after surgical procedure in group IPC, neurological assessment was done. Hind limbs neurologic function was assessed using the Tarlov Scoring System [17]. A score of 0-5 was assigned to each animal as follows: $0=$ no voluntary hind limb movement; $1=$ movement of joints perceptible; $2=$ active movement but unable to sit without assistance; $3=$ able to sit but unable to hop; $4=$ weak hop; $5=$ complete recovery of hind limb function. The placing/stepping reflex (SPR) was assessed by dragging the dorsum of the hind paw along the edge of a surface. This normally evokes a coordinating lifting and placing response which was graded as follows: $0=$ normal; 1 = weak; and 2 = no stepping [18]. Sensory function was assessed by a hind limb withdrawal from a noxious stimulus $(1=$ withdrawal response to a stimulus applied to hind limbs and $0=$ no response to a stimulus). One member of the research team, was blinded to the different groups, conducted all neurological tests.

\subsection{Blood sampling and biochemical measurements}

After the neurological assessment, retroorbital blood samples were obtained through nonheparinized capillary tubes after overnight fasting. Samples were allowed to clot for 20 minutes at $37^{\circ} \mathrm{C}$ water bath, then, centrifuged at $14,000 \mathrm{rpm}$ for 10 minutes for serum separation and used for determination of tumor necrosis factor alpha $(\mathrm{TNF}-\alpha)$ level.

\subsection{Determination of serum TNF- $\alpha$ level}

TNF- $\alpha$ level was measured by cytotoxicity on L929 cells by enzyme-linked immunosorbent assay, using recombinant human TNF- $\alpha$ (BASF/Knoll, Ludwigshafen, Germany; specific activity $10^{7} \mathrm{U} / \mathrm{mg}$ ) and expressed in $\mathrm{pg} / \mathrm{mL}$ [19].

\subsection{Preparation of small intestinal and spinal cord homogenates}

After obtaining the blood samples, all rats were killed using a lethal dose of thiopental sodium injection [17]. For small intestinal homogenate preparation, $3 \mathrm{~cm}$ of rat jejunum were washed two times with cold saline solution and homogenized using an Omni tissue homogenizer 
(Omni international, Gainesville, VA, USA) in buffer at a ratio of $1 / 10(50 \mathrm{mM}$ potassium phosphate buffer $\mathrm{pH}$ : 7.8 , containing $0.5 \mathrm{mM} / \mathrm{L}$ PMSF, $10 \mu \mathrm{g} / \mathrm{mL}$ aprotinin). The homogenate was centrifuged at $2500 \mathrm{x}$ g for 10 minutes at $4^{\circ} \mathrm{C}$. The supernatants were then stored at $-80^{\circ} \mathrm{C}$ till the time of estimation of catalase (CAT) activity and malondialdehyde (MDA) level in the homogenate. For spinal cord homogenate preparation, sections of the 3,4, 5 lumbar segments of the spinal cord were harvested, dissected out, sliced into small pieces and homogenized using an Omni tissue homogenizer. Tissues were homogenized in icecold lyses buffer [0.1 M potassium phosphate, $\mathrm{pH}$ 7.4, $1 \mathrm{mM}$ EDTA, $10 \mu \mathrm{M}$ indomethacin (Cayman Chemical, Ann Arbor, MI, USA)] using a tube pestle. Acetone was added ( $2 \mathrm{x}$ sample volume), and samples were centrifuged at $1500 \mathrm{x} \mathrm{g}$ for 10 minutes at $4^{\circ} \mathrm{C}$. The supernatants were then stored at $-80^{\circ} \mathrm{C}$ till the time of estimations [21].

\subsection{Estimation of spinal cord homogenate levels}

of MDA and advanced oxidative protein product (AOPP) levels and Nitrite/Nitrate (NOx) as well as SOD and CAT activities

Lipid peroxidation was assessed by the measurement of secondary product MDA after precipitation of protein by addition of trichloroacetic acid then thiobarbituric acid (TBA) which reacted with MDA to form TBA reactive product, which was measured at $532 \mathrm{~nm}$. MDA solution, freshly made by the hydrolysis of 1,1,3,3-tetramethoxypropane, was used as a standard [21]. Determination of AOPP was based on spectrophotometric method detection (Shimadzu Corporation, Kyoto, Japan, UV- 160A) with tissue homogenate diluted with PBS to 0.2$0.5 \mathrm{~g} / \mathrm{mL}$ with characteristic absorbance at $340 \mathrm{~nm}$ [22]. SOD activity was assayed following the method of Kakkar et al. [23]. The sample containing $5 \mu \mathrm{g}$ protein was mixed with sodium pyrophosphate buffer, phenazine methosulphate (PMT) and nitro blue tetrazolium (NBT). The reaction was started by the addition of NADH, incubated at $30^{\circ} \mathrm{C}$ and stopped by the addition of 1 $\mathrm{mL}$ of glacial acetic acid. The absorbance of the chromogen formed was measured at $560 \mathrm{~nm}$. One unit of SOD activity is defined as the enzyme concentration required to inhibit chromogen production by $50 \%$ in one minute per mg protein under the assay condition [23]. CAT activity was measured in homogenate by the method of Bonaventura et al. [24]. Five micrograms proteins from the homogenate were mixed with $2 \mathrm{~mL}$ of $7.5 \mathrm{mM} \mathrm{H}_{2} \mathrm{O}_{2}$ and a time scan was performed for 10 minutes at $240 \mathrm{~nm}$ at $25^{\circ} \mathrm{C}$. One unit of CAT activity is defined as the amount of enzyme decomposing $1 \mu \mathrm{M}$ of $\mathrm{H}_{2} \mathrm{O}_{2}$ per minute per milligram protein [24]. The method for estimation of total NOx level was based on the Griess reaction. Spinal cord homogenate nitrite/nitrate levels were measured after enzymatic conversion of nitrate $\left(\mathrm{NO}_{3}{ }^{-}\right)$to nitrite $\left(\mathrm{NO}_{2}{ }^{-}\right)$by nitrate reductase in the presence of NADPH. The oxidation of the coenzyme was monitored by the decrease in absorbance at $540 \mathrm{~nm}$. Results were expressed as $\mu \mathrm{M} / \mathrm{L}$ [25]. Small intestinal MDA homogenate level and CAT activity were done by the same technical manoeuvers as done for spinal cord homogenate.

\subsection{Spinal cord homogenate prostaglandin $\mathbf{E}_{2}$ (PGE $)_{2}$ determination}

Spinal cord homogenate levels of $\mathrm{PGE}_{2}$ were assayed using monoclonal enzyme immunoassay (EIA) kit. The EIA kit demonstrates sensitivity from 10 to $1000 \mathrm{pg} / \mathrm{ml}$ and demonstrates little cross reactivity between structurally related $\mathrm{PE}_{3}$ and $\mathrm{PE}_{1}$. Absorbance (412 $\mathrm{nm})$ values of standards and samples were corrected by subtraction of the background value to correct for absorbance caused by nonspecific binding [26].

\subsection{Chemicals}

Nitrate reductase from Aspergillus was supplied by Sigma (St Louis, MO, USA) that utilizes polyoxyl-35- Ricinusolle as an emulsifier; ketamine hydrochloride was supplied by Pfizer Pharmaceutical Company, Inc, USA. Thiopental sodium was supplied by Biocheme, Austria; heparin and protamine sulfate was ordered from Leo, Ballerup (Denmark); Prostaglandin $\mathrm{E}_{2}$ EIA kit and indomethacin were purchased from Cayman Chemical, Ann Arbor, MI, USA.

\subsection{Statistical analysis}


Data were expressed as frequency, percentage and mean \pm SD. Testing significance was performed using $\chi^{2}$-test and the one-way analysis of variance (ANOVA). Post-hoc Scheffe test was applied to identify the source of statistical significance. P-values $<0.05$ were considered as statistically significant.

\section{Results}

The transient induction of intestinal IPC in rats did not produce any significant changes in small intestinal homogenate level of CAT or MDA activity compared with the control levels [Fig. 1]. Both the sham and the IPC groups did not show any significant changes in all measured parameters compared with the control group or with each others

\subsection{Serum level of TNF- $\alpha$ and $\mathrm{PGE}_{2}$ spinal cord homogenate level}

Induction of SC-IRI in rats produced significant elevation of serum TNF- $\alpha(10.2 \pm 1.41$ $\mathrm{pg} / \mathrm{mL}$ ) and spinal cord homogenate of $\mathrm{PGE}_{2}$ $(30.1 \pm 2.7 \mathrm{pg} / \mathrm{mL})$ levels compared with the control groups [C $(2.7 \pm 0.11 \mathrm{pg} / \mathrm{mL})$, sham $(2.8 \pm 0.63 \mathrm{pg} / \mathrm{mL})$ and IPC $(3.1 \pm 0.23 \mathrm{pg} / \mathrm{mL})$, $(\mathrm{P}<0.001)]$ and $[\mathrm{C} \quad(17.3 \pm 1.5 \mathrm{pg} / \mathrm{mL})$, sham
$(20.2 \pm 1.8 \mathrm{pg} / \mathrm{mL})$ and IPC $(18.1 \pm 1.9 \mathrm{pg} / \mathrm{mL})$, $(\mathrm{P}<0.001)]$ respectively. On the other hand, induction of intestinal rIPC 24 hours before SCIRI resulted in significant reduction of the serum TNF- $\alpha(6.2 \pm 0.81 \mathrm{pg} / \mathrm{mL})(\mathrm{P}<0.001)$ and spinal cord homogenate of $\mathrm{PGE}_{2} \quad(25.3 \pm 1.7 \mathrm{pg} / \mathrm{mL})$ $(\mathrm{P}<0.05)$ levels compared with $\mathrm{SC}-\mathrm{IRI}$ group or control groups (Fig. 2A and 2B), while serum TNF- $\alpha$ level did not show any significant changes in either the sham or IPC groups.

\subsection{Spinal cord homogenate activities of SOD and CAT}

Induction of SC-IRI in rats resulted in significant elevation of the SOD activity $(10.1 \pm 1.0$ unit $/ \mathrm{min} / \mathrm{mg}$ protein) and significant reduction of CAT activity $\left[1.4 \pm 0.3\left(\mu \mathrm{mol} \mathrm{H}_{2} \mathrm{O}_{2}\right.\right.$ decomposed $/ \mathrm{min} / \mathrm{mg}$ protein)] in the spinal cord homogenate compared with the control group $[(7.4 \pm 0.9$ unit $/ \mathrm{min} / \mathrm{mg}$ protein) $(\mathrm{p}<0.05)$ and $[4.1 \pm 0.5(\mu \mathrm{mol}$ $\mathrm{H}_{2} \mathrm{O}_{2}$ decomposed $/ \mathrm{min} / \mathrm{mg}$ protein $\left.)\right](\mathrm{p}<0.001)$ respectively]. On the other hand the SC-IRI+IPC group showed a significant reduction in SOD $(7.1 \pm 0.8 \mathrm{unit} / \mathrm{min} / \mathrm{mg}$ protein $)(\mathrm{p}<0.05)$ and a significant increase in CAT $\left[2.7 \pm 0.6\left(\mu \mathrm{mol} \mathrm{H}_{2} \mathrm{O}_{2}\right.\right.$ decomposed $/ \mathrm{min} / \mathrm{mg}$ protein $)](\mathrm{p}<0.05)$ activities compared with the SC-IRI group (Fig. 3A and 3B).
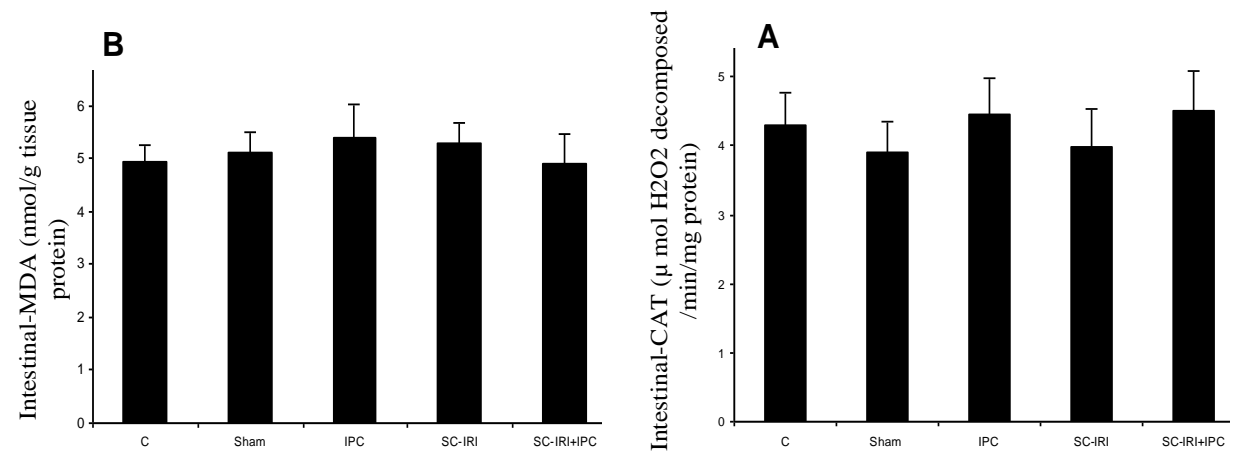

Figure 1. Effect of remote intestinal ischemic preconditioning (IPC) on catalase enzyme (CAT) activity [A] and malondialdehyde (MDA) level [B] in small intestinal homogenate. C: Control group; Sham: sham group; IPC: intestinal preconditioning without spinal ischemic cord injury group; SC-IRI: Spinal cord ischemic reperfusion injury group; SC-IRI+IPC: remote intestinal IPC in spinal cord ischemic reperfusion injury group.

Results are expressed as mean $\pm \mathrm{SD}(\mathrm{n}=10)$.

All differences between groups are not statistically significant. 

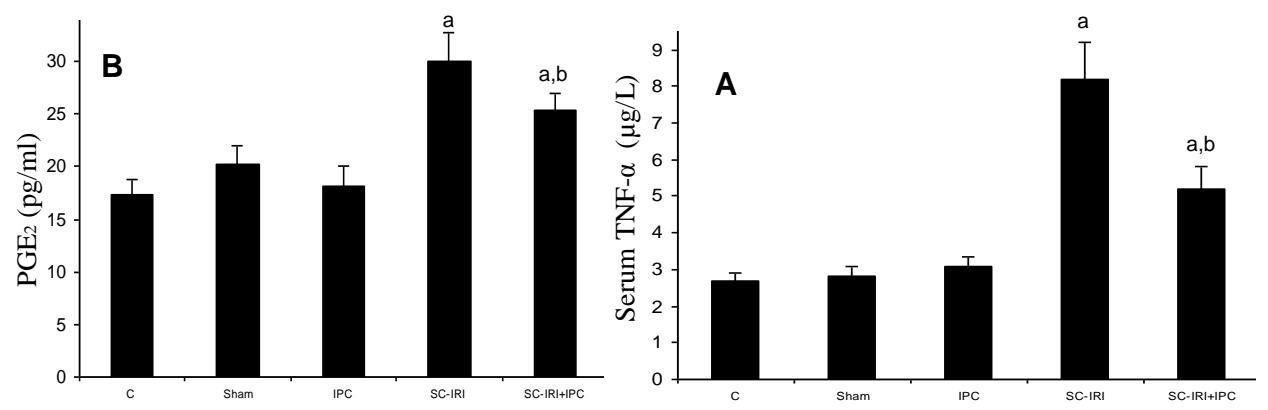

Figure 2. Effect of remote intestinal ischemic preconditioning (IPC) on serum TNF- $\alpha$ [A] and prostaglandin $E_{2}\left(\mathrm{PGE}_{2}\right)$ [B] levels in spinal cord homogenate. Control group; Sham: sham group; IPC: intestinal preconditioning without spinal ischemic cord injury group; SC-IRI: Spinal cord ischemic reperfusion injury group; SC-IRI+IPC: remote intestinal IPC in spinal cord ischemic reperfusion injury group.

Results are expressed as mean $\pm \mathrm{SD}(\mathrm{n}=10)$.

a. Significant difference, as compared with the control groups (C, Sham, IPC).

b. Significant difference, as compared with the SC-IRI group.
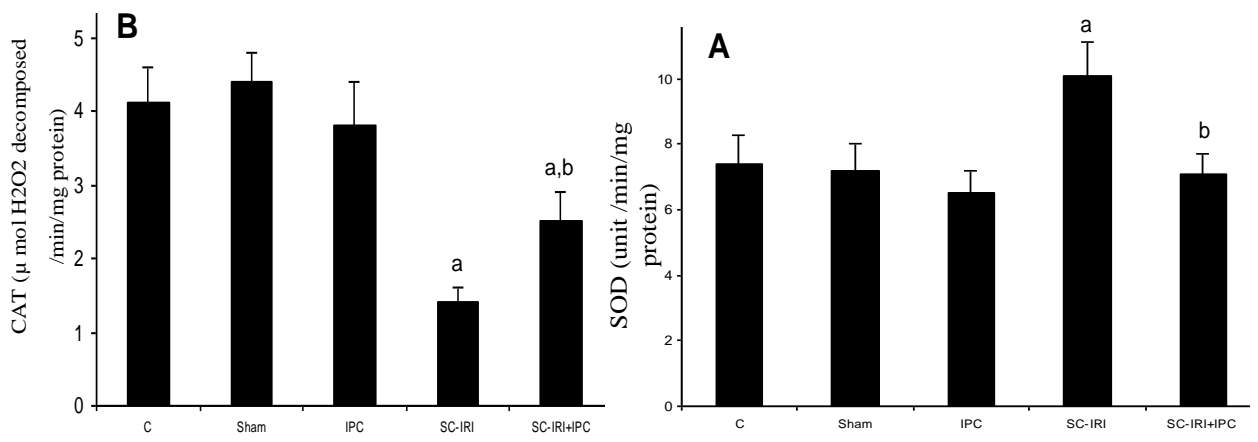

Figure 3. Effect of remote intestinal ischemic preconditioning (IPC) on superoxide dismutase (SOD) [A] and catalase (CAT) [B] activities in spinal cord homogenate. C: Control group; Sham: sham group; IPC: intestinal preconditioning without spinal ischemic cord injury group; SC-IRI: Spinal cord ischemic reperfusion injury group; SC-IRI+IPC: remote intestinal IPC in spinal cord ischemic reperfusion injury group.

Results are expressed as mean $\pm \mathrm{SD}(\mathrm{n}=10)$.

a. Significant difference, as compared with the control groups (C, Sham, IPC).

b. Significant difference, as compared with the SC-IRI group.

\subsection{Spinal cord homogenate levels of MDA, AOPP and NOx}

Lipid oxidative product MDA $[6.1 \pm 0.6(\mathrm{nmol} / \mathrm{g}$ tissue protein)], protein oxidative product AOPP $(7.5 \pm 0.9(\mu \mathrm{mol} / \mathrm{mg}$ protein $)$ and NOx levels $(0.233 \pm 0.029(\mathrm{nmol} / \mathrm{g}$ wet tissue) levels in spinal cord homogenate increased significantly in SC-IRI group compared with the control groups [C $(2.9 \pm 0.3 \quad(\mathrm{nmol} / \mathrm{g}$ tissue protein $)), \quad(3.8 \pm 0.4$ $(\mu \mathrm{mol} / \mathrm{mg}$ protein $))$ and $(0.161 \pm 0.018(\mathrm{nmol} / \mathrm{g}$ wet tissue)), $(\mathrm{P}<0.001)]$ respectively. While induction of intestinal rIPC in SC-IRI+IPC group produced significant reduction spinal cord homogenate levels of MDA (4.1 \pm 0.4 (nmol/g tissue protein)), 
AOPP $(5.1 \pm 0.7(\mu \mathrm{mol} / \mathrm{mg}$ protein $))$ and NOx $(0.171 \pm 0.021$ (nmol/g wet tissue) $)$ compared with the SC-IRI group (p<0.05) (Fig. 4A, 4B and 4C).

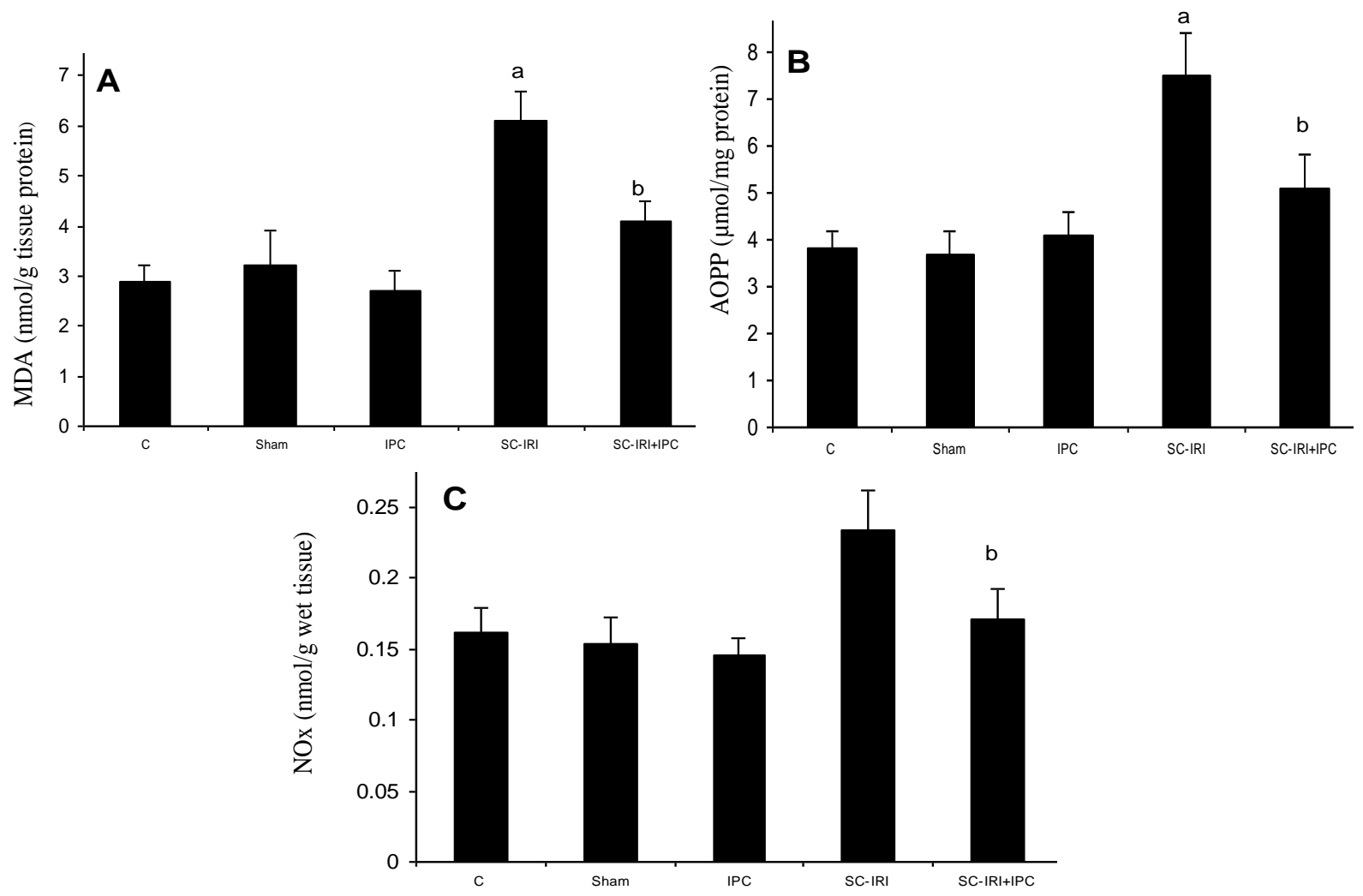

Figure (4): Effect of remote intestinal ischemic preconditioning (IPC) on malondialdehyde (MDA) [A], advanced oxidative protein product (AOPP) $[\mathrm{B}]$ and Nitrite/Nitrate $(\mathrm{NOx})[\mathrm{C}]$ activities in spinal cord homogenate. C: Control group; Sham: sham group; IPC: intestinal preconditioning without spinal ischemic cord injury group; SC-IRI: Spinal cord ischemic reperfusion Injury group; SC-IRI+IPC: remote intestinal IPC in spinal cord ischemic reperfusion injury group.

Results are expressed as mean $\pm \mathrm{SD}(\mathrm{n}=10)$.

a. Significant difference, as compared with the control groups (C, Sham, IPC).

b. Significant difference, as compared with the SC-IRI group.

\subsection{Motor, SPR and sensory assessment}

Rats in the SC-IRI group showed acute flaccid paraplegia of the hind limbs up to 6 hours after reperfusion injury followed by spastic paraplegia. Their motor score (mean $\pm \mathrm{SD}$ ) was (1.2 \pm 0.7$)$ compared with $(4.4 \pm 0.2)$ in the control group. Also sensory function was impaired in $66.6 \%$ of rats in the SC-IRI group, while SPR was lost in $33.3 \%$ and was impaired in $16.7 \%$ of SCIRI rats. On the other hand, induction of intestinal rIPC in SC-IRI group produced recovery of motor and sensory functions and SPR $(3.9 \pm 1.0,88.9 \%$ and $77.8 \%$, respectively) (Table 1 ).

\section{Discussion}

The major targets of this study were to demonstrate the remote effects of transient intermittent small intestinal IPC on the spinal cord ischemic-reperfusion injury and to investigate whether the intestinal tissues may suffer any significant deterioration in their oxidation markers during this procedure.

It is well documented that 40-60 minutes' ischemia produces ischemic tissue impairment which appears as early as 2 hours after reperfusion and reaches its peak 24 hours after reperfusion [9]. The evidence indicates that the spinal cord 
ischemia causes remarkable dysfunctional injuries and reperfusion actually aggravates the neurological damage [27]. Therefore, in the present study we induced SC-IRI by aortic artery occlusion for 45 minutes, followed by 24 hours reperfusion. The induced SC-IRI caused significant neurological deficit both motor and sensory. The neurological manifestations were associated with strong evidence of lipid peroxidation. Evidence of oxidative stress included the significant increase in serum TNF- $\alpha$ level and spinal cord homogenate levels of $\mathrm{PGE}_{2}$ and MDA in addition to AOPP and SOD activity with a significant reduction in CAT activity. The neurological deficits and their strong association with the markers of oxidative stress and inflammation have been strongly documented in previous studies [15]. The mechanisms responsible for SC-IRI are not fully understood. However, the reduction of CAT activity is possibly responsible for a number of deleterious effects in ischemic reperfusion injury due to the accumulation of $\mathrm{H}_{2} \mathrm{O}_{2}$ [28]. Lipid peroxidation, induced by reactive oxygen species (ROS) such as superoxide anion $\left(\mathrm{O}^{2-}\right)$, hydrogen peroxide $\left(\mathrm{H}_{2} \mathrm{O}_{2}\right)$, and hydroxyl radical $\left(\mathrm{OH}^{-}\right)$, has also been postulated to play an important role in postischemic acute spinal cord injury [28]. Alternatively, it has been proposed that inflammatory cells, especially neutrophils, are activated during ischemia, presumably by cytokines, and enter the spinal cord at the onset of reperfusion causing tissue damage by releasing ROS [8].

Table 1. Effect of remote intestinal IPC on SC-IRI in rats regarding scores of motor function, sensory response and placing/stepping reflex.

\begin{tabular}{|c|c|c|c|c|c|c|c|}
\hline & Test & $\mathrm{C}$ & Sham & IPC & SC-IRI & SC-IRI+IPC & $\mathrm{p}$-value \\
\hline $\begin{array}{c}\text { Motor } \\
\text { assessment }\end{array}$ & Mean \pm SD & $4.4 \pm 0.2$ & $4.6 \pm 0.5$ & $4.3 \pm 0.9$ & $1.2 \pm 0.7^{(\mathrm{a})}$ & $3.9 \pm 1.0^{(\mathrm{b})}$ & $\begin{array}{c}\mathrm{F}= \\
\mathrm{P}<0.001\end{array}$ \\
\hline \multirow{2}{*}{$\begin{array}{c}\text { Sensory } \\
\text { assessment }\end{array}$} & Normal & $\begin{array}{c}10 \\
(100 \%)\end{array}$ & $\begin{array}{c}9 \\
(100 \%)\end{array}$ & $\begin{array}{c}9 \\
(100 \%)\end{array}$ & $\begin{array}{c}2 \\
(33.3 \%)^{(a)}\end{array}$ & $\begin{array}{c}8 \\
(88.9 \%)^{(\mathrm{b})}\end{array}$ & \multirow{2}{*}{$\begin{array}{c}\chi^{2}= \\
\mathrm{p}<0.05\end{array}$} \\
\hline & Affected & $\begin{array}{c}0 \\
(0 \%)\end{array}$ & $\begin{array}{c}0 \\
(0 \%)\end{array}$ & $\begin{array}{c}0 \\
(0 \%)\end{array}$ & $\begin{array}{c}4 \\
(66.6 \%)^{(\mathrm{a})}\end{array}$ & $\begin{array}{c}1 \\
(11.1 \%)^{(b)}\end{array}$ & \\
\hline \multirow{3}{*}{$\begin{array}{c}\text { Placing/ } \\
\text { Stepping } \\
\text { Reflex }\end{array}$} & Normal & $\begin{array}{c}10 \\
(100 \%)\end{array}$ & $\begin{array}{c}9 \\
(100 \%)\end{array}$ & $\begin{array}{c}9 \\
(100 \%)\end{array}$ & $\begin{array}{c}3 \\
(50 \%)^{(a)}\end{array}$ & $\begin{array}{c}7 \\
(77.8 \%)^{(\mathrm{b})}\end{array}$ & \multirow{3}{*}{$\begin{array}{c}\chi^{2}= \\
p<0.01\end{array}$} \\
\hline & Impaired & $\begin{array}{c}0 \\
(0 \%)\end{array}$ & $\begin{array}{c}0 \\
(0 \%)\end{array}$ & $\begin{array}{c}0 \\
(0 \%)\end{array}$ & $\begin{array}{c}1 \\
(16.7 \%)^{(\mathrm{a})}\end{array}$ & $\begin{array}{c}1 \\
(11.1 \%)\end{array}$ & \\
\hline & Lost & $\begin{array}{c}0 \\
(0 \%)\end{array}$ & $\begin{array}{c}0 \\
(0 \%)\end{array}$ & $\begin{array}{c}0 \\
(0 \%)\end{array}$ & $\begin{array}{c}2 \\
(33.3 \%)^{(\mathrm{a})}\end{array}$ & $\begin{array}{c}1 \\
(11.1 \%)\end{array}$ & \\
\hline
\end{tabular}

C: Control group; Sham: sham group; IPC: intestinal preconditioning without spinal ischemic cord injury group; SCIRI: Spinal cord ischemic reperfusion Injury group; SC-IRI+IPC: remote intestinal IPC in spinal cord ischemic reperfusion injury group.

Results are expressed as mean $\pm \mathrm{SD}(\mathrm{n}=10)$.

$P$ value $<0.05$ is considered significant.

a. Significant difference, as compared with the control groups (C, Sham, IPC).

b. Significant difference, as compared with the SC-IRI group. 
The high serum NOx and TNF- $\alpha$ level in spinal cord homogenate, shown in the SC-IRI group, indicate iNOS activation, with subsequent increased inflammatory processes. The contribution of this process to the neurological damage has also been documented. Naik et al. [29] reported that, vascular neurological injuries stimulate iNOS activity with subsequent NO overproduction. This induces the formation of inflammatory cytokines, such as TNF- $\alpha$ and interleukin-1, with subsequent activation of COX2 and $\mathrm{PGE}_{2}$ overproduction. Consistent with this, Nogawa et al. [30] found that COX-2 mRNA expression in the brain peaked 12 hours after middle cerebral artery occlusion with concomitant iNOS over-expression. Another factor contributing to the ischemic reperfusion induced $\mathrm{NO}$ overproduction may be the reduction of the nuclear factor kappaB-dependent proinflammatory factors which play a major role in the activation of iNOS during the inflammatory process [31].

The small intestine is known as one of the most susceptible organs to ischemic reperfusion injury and is a primary site for overproduction of oxidant species and inflammatory cytokines after reperfusion [32]. These oxidant and inflammatory agents are most likely responsible for the remote organ injury observed after intestinal ischemic reperfusion injury [32]. However, pretreatment with brief small intestine ischemic reperfusion, not only elicits a local protective effect [9], but also remotely protects other organs like the heart and kidney from subsequent ischemic-reperfusion insults $[10,15]$. In this study we found that intermittent small intestinal rIPC similarly protected the spinal cord from IRI, while the small intestinal tissues did not suffer any significant deterioration of the oxidative markers (Figure 3). The neuroprotection, evident 24 hours after the SC-IRI, was demonstrates by significant improvement of motor and sensory function with preservation of the placing steeping reflex in the SC-IRI+IPC group. Serum TNF- $\alpha$ levels and the spinal cord homogenate levels of $\mathrm{PGE}_{2}, \mathrm{NOx}$, MDA, and AOPP and SOD activity were significantly decreased, while CAT activity was significantly increased in the SC-IRI+IPC group compared to the SC-IRI. These results suggested that, intermittent rIPC of the small intestine protects against increased oxidative stress level and inflammatory mediators via inhibition of lipid peroxidation and preservation of the endogenous antioxidants enzyme activities in SC-IRI. Our results are in agreement with Song et al, who reported that intestinal preconditioning resulted in a reduction in lipid peroxidation and preservation of antioxidant enzyme activities in rats subjected to renal ischemic reperfusion injury [14]. Dong et al, using hind limb ischemic preconditioning demonstrated a similar remote neuroprotective effect on the spinal cord [1]. Ates et al. also observed remote protective effects, employing hepatic ischemic preconditioning, in rats subjected to renal ischemic reperfusion injury [33]. A significant observation in this study is that, 48 hours after the ischemic episodes, the small intestinal homogenate levels of CAT and MDA activity were within in the normal range.

Several studies attempted to explain the mechanisms of rIPC between various organs. Although ROS are involved in the harmful effects of reperfusion on tissues after ischemia, their generation from brief ischemic reperfusion is the possible "trigger' for the initiation of preconditioning [34]. This protection could also be mediated through inhibition of the iNOS and COX-2 activity with modulation of the heat shock proteins [13]. Rüdiger et al suggested that IPC can induce energy-saving mechanisms, thereby decreasing the level of ATP degradation with subsequent accumulation of lactate throughout the ischemic period [34]. Gurcun et al. demonstrated the effectiveness of direct IPC and rIPC on the prevention of spinal cord ischemic injury and reported the protective values of reduced levels of neuron-specific enolase, malondialdehyde and nitric oxide [35]. Tang et al attributed the rIPC induced between the myocardium and the renal tissue to adenosine receptors and ATP-sensitive potassium channels [36]. Patel et al. demonstrated that intestinal rIPC resulted in reduction of the infarct size during myocardial ischemia via an opioid sensitive mechanism [37]. Beside humoral mediators, neurogenic mechanisms have been implicated as mediators of rIPC [13]. Whether the small intestinal $r$ IPC protective effect is related to 
humoral, neurogenic mechanisms or both, deserves further investigation.

\section{Conclusions}

Intermittent, transient, small intestinal ischemic preconditioning ameliorated the clinical neurological dysfunction induced by ischemic reperfusion injury of spinal cord. This ameliorating effect appears to be through reduction of the oxidative stress level and inflammatory mediators in the spinal cord.

As spinal cord ischemia-induced paraplegia remains a serious complication of ischemic reperfusion injury, prophylactic transient intestinal ischemic preconditioning appears to have promising potential as a preventive tool and warrants further and more exhaustive research.

\section{Competing interests}

The authors declare that they have no competing interests.

\section{Acknowledgements}

Thanks to all staff members and technicians of the Physiology Lab of Faculty of Medicine, King Khalid University, Saudi Arabia and College of Medicine, Menoufiya and Beni Suef Universities, Egypt for their great help in every step in this work. This work is considered as collaboration between Faculty of Medicine, King Khalid University, Saudi Arabia, College of Medicine, Menoufiya University and College of Medicine, Beni Suef University.

\section{References}

1. Dong, H.L.; Zhang, Y.; Su, B.X.; Zhu, Z.H.; Gu QH, Sang, H.F.; Xiong, L. Limb remote ischemic preconditioning protects the spinal cord from ischemia-reperfusion injury: a newly identified nonneuronal but reactive oxygen species-dependent pathway. Anesthesiology, 2010,112(4),881-91. PMID: 20216397

2. Saito, T.; Tsuchida, M.; Umehara, S.; Kohno, T.; Yamamoto, H.; Hayashi, J. Reduction of spinal cord ischemia/reperfusion injury with simvastatin in rats. Anesth Analg., 2011, 113(3), 565-571.

3. Sakurai, M.; Hayashi, T.; Abe, K.; Aoki, M.; Sadahiro, M.; Tabayashi, K. Enhancement of heat shock protein expression after transient ischemia in the preconditioned spinal cord of rabbits. J Vasc Surg., 1998, 27,720-725. PubMed PMID: 9576086

4. Yashin, A.; Yashin, Y.; Nemzer, B; Determination of Antioxidant Activity in Tea Extracts, and Their Total Antioxidant Content. Am. J. Biomed. Sci., 2011, 3(4), 322-335. ISSN: 1937-9080

5. Winrow, V.R.; Winyard, P.G.; Morris, C.J.; Blake, D.R. Free radicals in inflammation: second messengers and mediators of tissue destruction. Br Med Bul,l 1993, 49,506-522. ISSN 1471-8391

6. Morsy, D.M.; Mostafa, A.O.; Hassan, N.W. A potential protective effect of $\alpha$-tocopherol on vascular complication in spinal cord reperfusion injury in rats. Journal of Biomedical Science, 2010, 17-55. PMCID: PMC2909177.

7. Kaur, J.; Sanyal, S.N. Oxidative Stress and Stress-signaling in Chemoprevention of Early Colon Cancer by Diclofenac. Am. J. Biomed. Sci., 2010, 2(1),63-78. DOI: 10.5099/aj100100063.

8. Kulmacz, R.J.; Wang, L.H. Comparison of hydroperoxide initiator requirements for the cyclooxygenase activities of prostaglandin $\mathrm{H}$ synthase-1 and -2. J Biol Chem., 1995, 270 (41),24019-24023. PMID: 7592599.

9. Sileri, P.; Sica, G.; Gentileschi, P.; Venza, M.; Manzelli, A.; Palmieri, G.; Spagnoli, L.G.; Testa, G.; Benedetti, E.; Gaspari, A.L. Ischemic preconditioning protects intestine from prolonged ischemia. Transplant Proc., 2004, 36,283-285. PubMed PMID:15010362.

10. Gho, B.C.; Schoemaker, R.G.; van den Doel, M.A.; Duncker, D.J.; Verdouw, P.D. Myocardial protection by brief ischemia in noncardiac tissue. Circulation, 1996, 94,21932200. DOI: 10.1161/01.CIR.94.9.2193

11. Su, B.; Dong, H.; Ma, R.; Zhang, X.; Ding, Q.; Xiong, L. Cannabinoid 1 receptor mediation of spinal cord ischemic tolerance induced by limb 
remote ischemia preconditioning in rats. $J$

Thorac Cardiovasc Surg., 2009, 138(6),1409-

1416. PubMed: 19709680.

12. Joo, J.D.; Kim, M.; D’Agati, V.D.; Lee, H.T. Ischemic preconditioning provides both acute and delayed protection against renal ischemia and reperfusion injury in mice. $J A m$ Soc Nephrol., 2006, 20,1681-1689. DOI: 10.1681/ASN.2006050424 JASN

13. Birnbaum, Y.; Hale, S.L.; Kloner, R.A. Ischemic preconditioning at a distance: reduction of myocardial infarct size by partial reduction of blood supply combined with rapid stimulation of the gastrocnemius muscle in the rabbit. Circulation, 1997, 96,1641- 1646. DOI: 10.1161/01.CIR.96.5.1641

14. Song, T.; Peng, Y.; Guo, S.; Liu, Y.; Liu, L. Brief Small Intestinal Ischemia Lessens Renal Ischemia-reperfusion Injury in Rats. American Association for Laboratory Animal Science, 2007, 57(2),200-205. PMID: 17536621

15. Akguna, S.; Tekelia, A.; Kurtkayab, O.; Civeleka, A.; Isbira, S.; Aka, K.; Arsanc, S.; Savb, A. Neuroprotective effects of FK-506, Lcarnitine and azathioprine on spinal cord ischemia-reperfusion injury. European Journal of Cardio-thoracic Surgery, 2004, 25,105-110. PMID: 14690740

16. Taira, Y.; Marsala, M. Effect of proximal arterial perfusion pressure on function, spinal cord blood flow, and histopathological changes after increasing intervals of aortic occlusion in the rat. Stroke, 1996, 27,1850-1858. DOI: 10.1161/01.STR.27.10.1850

17. Tarlov, I.M. Acute spinal cord compression paralysis. J Neurosurg., 1972, 36,10-20. PMID: 5007267

18. Marsala, M.; Yaksh, T.L. Transient spinal ischemia in the rat: characterization of behavioral and histopathological consequences as a function of the duration of aortic occlusion. J Cereb Blood Flow Metab.,1994, 14,526 -535. DOI:10.1038/jcbfm.1994.65.

19. Barber, E.; Menedez, S.; León, O.S.; Barber, M.O.; Merino, N.; Calunga, J.L.; Cruz, E.; Bocci, V. Prevention of renal injury after induction of ozone tolerance in rats submitted to warm ischemia. Mediators Inflamm., 1999, 8(1),37-41. PMID: 10704088
20. Zvara, D.A.; Andrew, J.B.; Deal, D.D.; De Marco, M.P.; Campos, K.M.; Mansfield, C.M.; Tytell, M. Anesthetic Preconditioning with Sevoflurane Does Not Protect the Spinal Cord After an Ischemic-Reperfusion Injury in the Rat. Anesth Analg., 2006, 102,1341-1347. PMID: 16632806.

21. Ohkawa, H.; Ohishi, N.; Yagi, K. Assay for lipid peroxides in animal tissues by thiobarbituric acid reaction. Anal Biochem.; 1979, 95,351-358. PMID:36810.

22. Kalousova, M.; Skrha, J.; Zima, T. Advanced glycation endproducts and advanced oxidation protein products in patients with diabetes mellitus. Physiol Res., 2002, 51,597-604. ISSN $\underline{0862-8408}$

23. Kakkar, P.; Das, B.; Viswanathan, P.N. A modified spectrophotometric assay of superoxide dismutase. Indian $J$ Biochem Biophys., 1984, 21,130-132. PMID: 6490072.

24. Bonaventura, J.; Schroeder, W.A.; Fang, S. Human erythrocyte catalase: an improved method of isolation and revaluation of reported properties. Arch Biochem Biophys., 1972, 150,606-617. PMID: 5044042.

25. Green, L.C.; Tannenbaum, S.R.; Goldman, P. Nitrate synthesis in the germfree and conventional rat. Science, 1981, 212,56 -58. DOI:10.1126/science.6451927.

26. Zhao, P.; Stephen, G.; Waxman, S.G.; Hains, B.C. Neurobiology of Disease Extracellular Signal-Regulated Kinase Regulated MicrogliaNeuron Signaling by Prostaglandin E2 Contributes to Pain after Spinal Cord Injury. Journal of Neuroscience, 2007, 27(9),23572368.

27. Varija, D.; Kumar, K.; Reddy, K.; Reddy, V. Prolonged constriction of sciatic nerve affecting oxidative stressors and antioxidant enzymes in rat. Indian J Med Res., 2009, 129,587-592. PMID: 19675389.

28. Burns, B.J.; Brandt, L.J. Intestinal ischemia. Gastroenterol Clin North Am., 2003, 32,11271143. PMID: 14696300.

29. Naik, A.K.; Tandan, S.K.; Dudhgaonkar, S.P.; Jadhav, S.H.; Kataria, M.; Prakash, V.R.; Kumar, D. Role of oxidative stress in pathophysiology of peripheral neuropathy and modulation by N-acetyl-L-cysteine in rats. Eur 
30. $J$

Pain, 2006,

10,573-579.

DOI.org/10.1016/j.ejpain.2005.08.006

31. Nogawa, S.; Forster, C.; Zhang, F.; Nagayama, M.; Ross, M.E.; Iadecola, C. Interaction between inducible nitric oxide synthase and cyclooxygenase-2 after cerebral ischemia. Proc Natl Acad Sci., 1998,95,10966-10971. PMCID: PMC28004

32. Zhang, Y.; Wu, Y.X.; Hao, Y.B.; Dun, Y.; Yang, S.P. Role of endogenous opioid peptides in protection of ischemic preconditioning in rat small intestine. Life Sci., 2001,68,1013-1019. DOI.org/10.1016/S0024-3205(00)01004-3.

33. Turnage, R.H.; Guice, K.S.; Oldham, K.T. Endotoxemia and remote organ injury following intestinal reperfusion. J Surg Res., 1994,56,571-578. PMID: 8015313.

34. Ates, E.; Genc, E.; Erkasap, N.; Erkasap, S.; Akman, S.; Firat, P.; Emre, S.; Kiper, H. Renal protection by brief liver ischemia in rats. Transplantation, 2002,15,1247-1251. PMID: 12451261.

35. Rüdiger, H.A.; Graf, R.; Clavien, P.A. Sublethal oxidative stress triggers the protective effects of ischemic preconditioning in the mouse liver. J Hepatol., 2003,39(6),972-977. PubMed PMID: 14642614.

36. Gurcun, U.; Discigil, B.; Boga, M.; Ozkisacik, E.; Badak, M.I.; Yenisey, C.; Kurtoglu, T.; Meteoglu, I. Is remote preconditioning as eff ective as direct ischemic preconditioning in preventing spinal cord ischemic injury?. J Surg Res., 2006, 135,385-393. PubMed PMID: 16904694.

37. Tang, Z.L.; Dai, W.; Li, Y.J.; Deng, H.W. Involvement of capsaicin sensitive sensory nerves in early and delayed cardioprotection induced by a brief ischemia of the small intestine. Naunyn Schmiedebergs Arch Pharmacol., 1999, 359,243-247. DOI: 10.1007/PL00005348.

38. Patel, H.H.; Moore, J.; Hsu, A.K.; Gross, G.J. Cardioprotection at a distance: mesenteric artery occlusion protects the myocardium via an opioid sensitive mechanism. J Mol Cell Cardiol., 2002, 34,1317-1323. PubMed PMID: 12392992. 